\title{
Is suicide underreported? Evidence from Japan
}

\author{
Tetsuya Matsubayashi ${ }^{1}$ (D) $\cdot$ Michiko Ueda $^{2}$
}

Received: 6 April 2021 / Accepted: 31 October 2021 / Published online: 12 November 2021

(c) The Author(s) 2021

\begin{abstract}
Purpose The underreporting of suicides has been a serious global concern among scholars and policymakers. Several studies have sought to detect the prevalence of underreporting by examining whether suicide mortality rates are negatively correlated with those due to unknown intent or causes. This study adds to the literature by examining the potential underreporting of suicides in Japan, where suicide rates have greatly declined in the recent years.

Methods We compiled subnational data from 47 prefectures between 1995 and 2016, obtained from Vital Statistics of Japan. We examined whether (1) mortality rates due to unknown intent or causes increased as suicide rates decreased; and (2) major socioeconomic causes of suicide (unemployment and divorce rates) had any relationship with the deaths due to unknown intent or causes.

Results Our analysis indicates that mortality rates due to unknown intent or causes were uncorrelated with suicide rates and the above socioeconomic indicators.

Conclusions In Japan, the frequency of suicides has no systematic relationship with deaths due to unknown intent or causes, suggesting the accuracy of suicide statistics.
\end{abstract}

Keywords Suicide $\cdot$ Mortality rate $\cdot$ Unknown causes $\cdot$ Underreporting $\cdot$ Japan

\section{Introduction}

Suicide is a serious public health concern worldwide. Scholars and policymakers have sought to identify the potential causes and effective prevention strategies of suicide, based on data obtained from suicide statistics. However, their accuracy has been questioned for many years (e.g., [1-5]). Suicides are likely to be underreported due to socio-cultural reasons, such as stigma and social pressures, and institutional reasons, such as the lack of resources for autopsy and rigorous classification of deaths $[2,6-10]$.

To understand the prevalence of underreporting in suicide statistics, scholars have developed several approaches and investigated whether and how likely suicides are misclassified as deaths due to other causes. The first approach (e.g., $[9,11])$ uses detailed death records and assesses the process of classifying the cause of deaths by suicide. The second

Tetsuya Matsubayashi

matsubayashi@osipp.osaka-u.ac.jp

1 Osaka School of International Public Policy, Osaka University, Osaka, Japan

2 Waseda University, Tokyo, Japan approach (e.g., $[12,13])$ treats probable suicides (e.g., deaths by unknown causes or unidentified intent, and unintentional poisoning and drowning) as suicidal deaths and assesses whether alternative suicide rates including probable suicides are significantly higher than only those deaths which are classified as suicides in the original registry. The third approach (e.g., [14-16]) assesses whether suicides and probable suicides have similar background characteristics, such as gender, age, and medical history. The fourth approach (e.g., [6, 17-22]) assesses whether suicide rates are correlated with mortality rates due to other causes, such as unidentified injury, unidentified intent, unknown causes, or unintentional poisoning, under the assumption that suicidal cases are misclassified as deaths due to other causes, and thus, the underreporting of suicide results in the overreporting of deaths by these causes. Although the findings differ significantly across approaches and regions, overall, the underreporting of suicides is a frequently occurring, global problem [23].

This study adds to the literature by studying the potential underreporting of suicide in Japan. Our contributions are threefold. First, our focus was on Japan, where the potential underreporting of suicide has not yet been systematically 
examined. Japan is particularly an interesting case because the suicide rate has dramatically declined in the recent years from 40.0 per 100,000 population in 2002 to 23.2 in 2017 [24]; this decline may be partly attributable to underreporting. Second, we employed a regression-based approach developed by Kapusta et al. [6]. We used subnational data compiled from the Vital Statistics of Japan between 1995 and 2016, and examined whether suicide rates decreased as deaths due to unidentified injury, intent, or unknown causes increased in 47 prefectures during our study period. Our fixed-effect regression model allowed us to test whether suicide rates were negatively correlated with mortality rates due to unidentified intent or unknown causes after controlling for prefecture-specific time-invariant characteristics, time-specific shocks, and prefecture-specific time trends, thus eliminating the influences of major confounding factors, such as institutional environments and culture. Mortality rates were computed separately by age and sex. Third, we examined whether major socioeconomic causes of suicide, particularly unemployment and divorce rates, had any relationship with deaths due to unknown intent or causes. If a large number of suicide cases were coded as deaths by unknown causes or intent, the unemployment and divorce rates might be able to explain the change in deaths due to these causes. This analysis is motivated by the second approach mentioned above, which examines whether suicides and probable suicides share similar socioeconomic characteristics.

\section{Methods}

The mortality data used in this study were obtained from death records preserved in the Vital Statistics of Japan. The data were collected for administrative purposes and anonymized and de-identified by the Ministry of Health, Labor and Welfare, before being released for research use. Individual death records were made available for research purposes by the Ministry. The vital statistics data are based on the death certificates issued by physicians and subsequently reported to the local government where the residency of the deceased is registered. The records cover all reported deaths in Japan, as well as those of Japanese citizens outside Japan. The records include the date of birth, date of death, reported place of death, and the underlying cause of death based on the International Classification of Diseases (ICD). Our study focused on the period between 1995 and 2016 because the ICD-10 standard became effective in 1995 in Japan; thus, we could use a consistent definition of deaths throughout our study.

Drawing on Kapusta et al. [6], we analyzed the data of deaths by suicide (X60-X84), unidentified intent (Y10-Y34), and unknown causes (R98 and R99). Note that we did not include deaths due to unknown causes coded as R00-R97 because the causes of deaths under these categories were partially known, though not fully determined. Moreover, their symptoms, such as symptoms and signs involving the circulatory and respiratory systems (R00-R09) and symptoms and signs involving the digestive system and abdomen (R10-R19), are rare in suicidal deaths. In Japan, all deaths due to external (or unnatural) causes, including the suspected cases, are reported to the police. Usually, a doctor assists the police in examining the circumstances to determine the cause of death before issuing a death certificate. Unless the cause of death is a suspected criminal activity, it is often determined without an internal examination. On an average, approximately $10 \%$ of deaths undergo internal examinations in Japan [25].

We excluded certain death records based on the following criteria: (1) Of individuals whose place of death was outside of Japan; (2) Records that did not include the date or place of death, because we will later aggregate the frequency of deaths by year and prefecture; and (3) Of individuals under the age of 19 because of the small number of suicide incidents in this age group.

We aggregated the individual death records by prefecture and year, producing panel data of mortality among 47 prefectures over 22 years. To consider the possibility that the underreporting of suicide was more prevalent among particular subpopulations, we tabulated the number of deaths for the above three causes by six age-sex groups: (1) men aged between 20 and 39 years, (2) men aged between 40 and 64 years, (3) men aged 65 years and over, (4) women aged between 20 and 39 years, (5) women aged between 40 and 64 years, and (6) women aged 65 years and over. We determined a mortality rate (the number of deaths per 100,000 population) for the six subgroups using population data from the Basic Resident Register for each year [26]. For each age-sex subgroup, the number of observations was 1034 ( $=47$ prefectures $\times 22$ years). The unit of observation was prefecture-year.

Using the mortality rate data of suicide, unidentified intent, and unknown causes in 47 prefectures between 1995 and 2016 for each of the six age-sex groups, we first examined whether suicide mortality rates were negatively correlated with those due to unidentified intent or unknown causes. We formulated the following model:

$$
\begin{aligned}
\text { [Suicide }_{j t}= & \beta_{1}[\text { Unidentified intent }]_{j t}+\beta_{2}[\text { Unknown cause }]_{j t} \\
& +\gamma_{j} T+\varphi_{t}+\rho_{j}+\varepsilon_{j t}
\end{aligned}
$$

where $[\text { Suicide }]_{j t}$, $[\text { Unidentified intent }]_{j t}$, and [Unknown cause $]_{j t}$ each denote a mortality rate per 100,000 population. If suspicious suicidal cases were coded as deaths by unidentified intent or unknown causes, $\beta_{1}$ and $\beta_{2}$ would be estimated to be negative, which would then suggest the potential underreporting of suicide. 
In Eq. (1), $\varphi_{t}$ represents the year fixed effects and $\rho_{j}$ represents the prefecture fixed effects unique to each prefecture, while $\gamma_{j} T$ represents the prefecture-specific linear time trends. The inclusion of the year fixed effects allowed us to control for the influences of annual socioeconomic fluctuations at the national level, such as the macroeconomic policies and business cycles, which might affect the mortality rate in the entire country. On the other hand, the inclusion of the prefecture fixed effects allowed us to control for the effects of time-invariant characteristics of prefectures, such as social norms related to suicide, climate and geographical conditions, and relatively stable autopsy-related practices. Furthermore, the inclusion of $\gamma_{j} T$ in the model allowed us to consider the linear (typically declining) trends in suicide rates unique to each prefecture. All these terms are crucial in our estimation because we aimed to isolate the relationship between suicide rates and mortality rates due to unidentified intent or unknown causes after controlling for these major potential confounders. Moreover, to account for the potential serial correlation in the error term within the prefectures and heteroskedasticity, the standard errors were clustered by prefecture.

Next, we examined whether the major socioeconomic causes of suicide (i.e., unemployment and divorce rates) had any relationship with mortality rates due to unknown intent or causes. We modified Eq. (1) as follows:

$$
\begin{aligned}
{\left[\text { Mortality }_{j t}=\right.} & \beta_{1}[\text { Unemployment }]_{j t}+\beta_{2}[\text { Divorce }]_{j t} \\
& +\gamma_{j} T+\varphi_{t}+\rho_{j}+\varepsilon_{j t},
\end{aligned}
$$

where the outcome variable [Mortality $]_{j t}$ denotes either $[\text { Suicide }]_{j t}$, [Unidentified intent $]_{j t}$, or $[\text { Unknown cause }]_{j t}$. $[\text { Unemployment }]_{j t}$ denotes the unemployment rate in percentages in prefecture $j$, in year $t$, and [Divorce $]_{j t}$ denotes the divorce rate per 1000 persons. They were obtained from the System of Social and Demographic Statistics of Japan [27]. The data of the unemployment rate in the prefectures were available only from 1997; therefore, we limited our analysis between 1997 and 2016. Thus, here, the number of observations was $940(=47$ prefectures $\times 20$ years $)$. The standard errors were clustered by prefecture.
These two socioeconomic variables are the major predictors of suicide worldwide (e.g., [28]). We anticipated that the deaths due to unidentified intent and unknown causes share the same underlying mechanism as suicides. Therefore, we analyzed whether the unemployment and divorce rates were positively correlated with the suicide rates in our data, and a similar relationship existed with the mortality rates due to unidentified intent and unknown causes. If the unemployment and/or divorce rates have a positive relationship with the mortality rates due to unidentified intent and unknown causes, it suggests that the classification of deaths due to unidentified intent and unknown causes might include some suicidal cases; thereby indicating the underreporting of suicides. Equations (1) and (2) were estimated using the ordinary least squares estimator and Stata software version 15 (Stata Corporation).

\section{Results}

Table 1 presents the total number of deaths due to suicide, unidentified intent, and unknown causes, for the six agesex groups between 1995 and 2016 in Japan. In addition, it reports the average population size of each subgroup between 1996 and 2016 to calculate a mortality rate during the study period. Table 2 reports the summary statistics of these variables. Suicide was reported as a cause of death more frequently than unidentified intent and unknown causes among all six age-sex groups. The relative frequencies of deaths due to unidentified intent and unknown causes was greater among middle-aged and older men and women. The relative size of deaths due to unknown causes among men and women aged 65 and over was particularly large.

Figure 1 displays the temporal changes in mortality rates by three types of deaths among the six age-sex groups and shows several interesting patterns. First, as mentioned above, the decline in suicide rate in the last decade was consistent across all the age-sex groups, but most evident among men aged 40-64 years, and both men and women aged 65 years and above. Second, these groups experienced a modest to large increase in mortality rates due to unknown causes after
Table 1 The total number of deaths due to suicide, unidentified intent, and unknown causes in Japan

\begin{tabular}{|c|c|c|c|c|c|c|}
\hline \multirow[t]{2}{*}{ Age groups } & \multicolumn{3}{|l|}{ Men } & \multicolumn{3}{|l|}{ Women } \\
\hline & $20-39$ & $40-64$ & 65 and over & $20-39$ & $40-64$ & 65 and over \\
\hline Suicide & 101,461 & 222,104 & 103,360 & 40,439 & 68,725 & 68,637 \\
\hline Unidentified intent & 5,661 & 13,491 & 9,264 & 2,884 & 5,260 & 7,084 \\
\hline Unknown causes & 5,386 & 35,820 & 45,251 & 2,119 & 7,565 & 30,898 \\
\hline $\begin{array}{l}\text { Average popula- } \\
\text { tion size between } \\
\text { 1995-2016 }\end{array}$ & $17,006,334$ & $21,588,614$ & $10,796,533$ & $16,303,056$ & $21,644,681$ & $14,737,517$ \\
\hline
\end{tabular}
(1995-2016)
Source: The Vital Statistics and the Basic Resident Register 
Table 2 Summary statistics

\begin{tabular}{lllll}
\hline & Mean & S.D. & Min & Max \\
\hline Mortality rate by suicide, men 20-39 & 28.922 & 7.095 & 10.053 & 57.744 \\
Mortality rate by suicide, women 20-39 & 10.579 & 3.034 & 1.231 & 21.551 \\
Mortality rate by suicide, men 40-64 & 49.587 & 14.223 & 21.245 & 108.217 \\
Mortality rate by suicide, women 40-64 & 14.184 & 2.978 & 5.534 & 25.202 \\
Mortality rate by suicide, men 65 and over & 45.952 & 11.531 & 16.862 & 103.074 \\
Mortality rate by suicide, women 65 and over & 22.397 & 8.187 & 4.172 & 66.824 \\
Mortality rate by unidentified intent, men 20-39 & 1.488 & 1.229 & 0.000 & 9.479 \\
Mortality rate by unidentified intent, women 20-39 & 0.721 & 0.758 & 0.000 & 5.663 \\
Mortality rate by unidentified intent, men 40-64 & 2.794 & 2.022 & 0.000 & 16.068 \\
Mortality rate by unidentified intent, women 40-64 & 1.090 & 0.958 & 0.000 & 6.178 \\
Mortality rate by unidentified intent, women 65 and over & 3.543 & 3.498 & 0.000 & 26.524 \\
Mortality rate by unidentified intent, women 65 and over & 2.033 & 1.836 & 0.000 & 14.586 \\
Mortality rate by unknown causes, men 20-39 & 1.299 & 1.181 & 0.000 & 13.026 \\
Mortality rate by unknown causes, women 20-39 & 0.505 & 0.664 & 0.000 & 5.987 \\
Mortality rate by unknown causes, men 40-64 & 6.710 & 5.929 & 0.000 & 36.540 \\
Mortality rate by unknown causes, women 40-64 & 1.424 & 1.447 & 0.000 & 7.954 \\
Mortality rate by unknown causes, men 65 and over & 14.908 & 17.712 & 0.000 & 139.031 \\
Mortality rate by unknown causes, women 65 and over & 7.895 & 10.139 & 0.000 & 85.873 \\
Population size, men 20-39 & 361,837 & 396,000 & 61,283 & $2,068,652$ \\
Population size, women 20-39 & 346,874 & 366,907 & 58,771 & $1,909,322$ \\
Population size, men 40-64 & 459,332 & 438,982 & 93,039 & $2,346,442$ \\
Population size, women 40-64 & 460,525 & 428,776 & 94,233 & $2,248,188$ \\
Population size, men 65 and over & 229,713 & 204,055 & 45,684 & $1,298,820$ \\
Population size, women 65 and over & 313,564 & 263,006 & 71,277 & $1,700,257$ \\
Unemployment rate (\%) & 4.027 & 1.089 & 1.700 & 8.400 \\
Divorce rate per 1000 & 1.849 & 0.305 & 1.060 & 2.940 \\
\hline & & & & \\
\hline
\end{tabular}

Table entries are the mortality rates for each cause of death per 100,000 population, population size, the unemployment, and divorce rates. The number of observations is $1034(=47$ prefectures $\times 22$ years $)$ for the mortality-related variables and $940(=47$ prefectures $\times 20$ years $)$ for the unemployment and divorce rates. The unit of observation is prefecture-year

2005. Notably, the mortality rates due to unknown causes exceeded those by suicide in 2015 among the elderly population, regardless of sex. Third, the mortality rates due to unidentified intent exhibited little change for all the agesex groups between 1995 and 2016. Overall, the decrease in the suicide rates and the increase in the mortality rate due to unknown causes among some groups suggests that some suicide deaths could have been coded as death due to unknown causes.

However, the above observations do not consider any time- or area-specific characteristics and changes. To test this possibility in a more rigorous manner, Table 3 reports the estimation results of Eq. (1), where the suicide rates were regressed on the mortality rates due to unidentified intent and unknown causes. The prefecture and year fixed effects and the prefecture-specific linear time trend were included in the estimation, but their coefficients and standard errors were not reported. According to Table 3, there was no statistically significant relationship between the mortality rates due to unidentified intent and unknown causes and the suicide rates across all the age-sex groups.

Table 4 reports the estimation results of Eq. (2), where the mortality rates due to the three causes of death were regressed on the unemployment and divorce rates. Similar to Table 3, the results of the prefecture and year fixed effects and the prefecture-specific linear time were not reported. Panel (1) of Table 4 focuses on the suicide rates as an outcome variable. As expected, the unemployment and divorce rates had a positive and statistically significant relationship with the male suicide rates. As the unemployment rate increased by 1 percent, the suicide rate per 100,000 increased by 1 among men aged 20-39, 4.2 among men aged 40-64, and 2.6 among men aged 65 and over. As the divorce rate increased by 1 per 1000 population, the suicide rate increased by 10 among young and senior men. Contrastingly, we found no significant relationship between these two socioeconomic indicators and female suicide rates. 

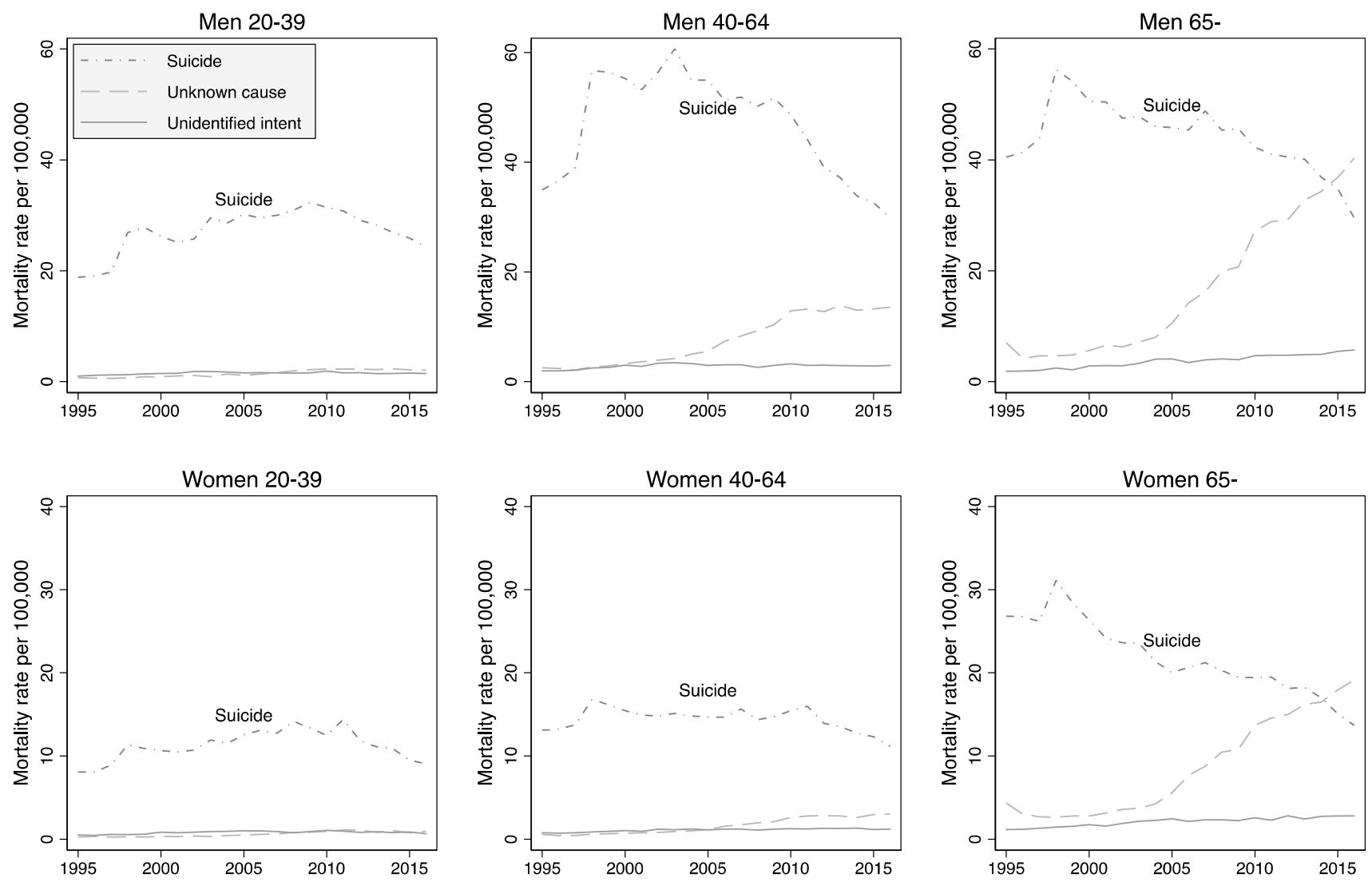

Source: The Vital Statistics.

Fig. 1 Mortality rates due to suicide, unidentified intent, and unknown causes by sex and age group in Japan, 1995-2016.

Table 3 The relationship of suicide rates with mortality rates due to unknown causes or unidentified intent in 47 prefectures in Japan (19952016)

\begin{tabular}{|c|c|c|c|c|c|c|}
\hline & \multicolumn{3}{|l|}{ Men } & \multicolumn{3}{|l|}{ Women } \\
\hline & $20-39$ & $40-64$ & 65 and over & $20-39$ & $40-64$ & 65 and over \\
\hline \multirow[t]{2}{*}{ Unidentified intent } & 0.134 & 0.031 & 0.031 & 0.249 & -0.039 & 0.006 \\
\hline & $(0.180)$ & $(0.048)$ & $(0.048)$ & $(0.225)$ & $(0.119)$ & $(0.034)$ \\
\hline \multirow[t]{2}{*}{ Unknown causes } & -0.016 & 0.088 & 0.088 & 0.048 & -0.087 & -0.078 \\
\hline & $(0.228)$ & $(0.099)$ & (0.099) & $(-0.191)$ & $(0.162)$ & $(0.113)$ \\
\hline$R^{2}$ & 0.508 & 0.785 & 0.568 & 0.362 & 0.346 & 0.693 \\
\hline$N$ & 1034 & 1034 & 1034 & 1034 & 1034 & 1034 \\
\hline
\end{tabular}

Table entries are linear regression estimates with standard errors in parentheses. The unit of observation is prefecture-year. The standard errors are clustered by prefecture. The outcome variable was the suicide rate per 100,000 people. All models include prefecture, year fixed effects and prefecture-specific linear time trends. $* p<0.10, * * p<0.05, * * * p<0.01$ (two-tailed tests)
Based on these results, we further tested whether these socioeconomic indicators were also strong predictors of the mortality rates due to unidentified intent and unknown causes. If some of the deaths coded as due to unidentified intent and unknown causes were actually suicide cases, we should be able to find a strong positive relationship between the major predictors of suicide and the mortality rates due to unidentified intent and unknown causes, especially among men. Panels (2) and (3) of Table 4 show the estimation results, where the mortality rates due to unidentified intent and unknown causes are the outcome variables. We found no statistically significant relationship between these causes and 
Table 4 The relationship between two measures of socioeconomic characteristics and mortality rates due to suicide, unidentified intent, and unknown causes in 47 prefectures in Japan (1997-2016)

\begin{tabular}{|c|c|c|c|c|c|c|}
\hline \multirow[t]{2}{*}{ (1) Suicide } & \multicolumn{3}{|l|}{ Men } & \multicolumn{3}{|l|}{ Women } \\
\hline & $20-39$ & $40-64$ & 65 and over & $20-39$ & $40-64$ & 65 and over \\
\hline \multirow[t]{2}{*}{ Unemployment rate } & $1.018^{*}$ & $4.191 * * *$ & $2.570 * * *$ & -0.129 & 0.194 & 0.564 \\
\hline & $(0.564)$ & $(0.957)$ & $(0.903)$ & $(0.277)$ & $(0.272)$ & $(0.532)$ \\
\hline \multirow[t]{2}{*}{ Divorce rate } & $10.343 * * *$ & 14.615 & $10.644 *$ & 0.494 & 1.437 & -3.892 \\
\hline & $(3.435)$ & $(9.212)$ & $(5.827)$ & $(1.942)$ & $(1.800)$ & (3.119) \\
\hline$R^{2}$ & 0.410 & 0.811 & 0.595 & 0.362 & 0.346 & 0.693 \\
\hline$N$ & 940 & 940 & 940 & 940 & 940 & 940 \\
\hline \multirow[t]{2}{*}{ (2) Unidentified intent } & \multicolumn{3}{|l|}{ Men } & \multicolumn{3}{|l|}{ Women } \\
\hline & $20-39$ & $40-64$ & 65 and over & $20-39$ & $40-64$ & 65 and over \\
\hline \multirow[t]{2}{*}{ Unemployment rate } & -0.120 & -0.127 & -0.086 & -0.010 & -0.019 & -0.297 \\
\hline & $(0.099)$ & $(0.192)$ & $(0.321)$ & $(0.084)$ & $(0.104)$ & $(0.207)$ \\
\hline \multirow[t]{2}{*}{ Divorce rate } & 0.933 & 0.442 & -1.053 & -0.571 & $-1.224 * * *$ & -1.735 \\
\hline & $(0.776)$ & $(1.035)$ & $(1.341)$ & $(0.509)$ & $(0.401)$ & (1.037) \\
\hline$R^{2}$ & 0.202 & 0.363 & 0.537 & 0.140 & 0.279 & 0.370 \\
\hline$N$ & 940 & 940 & 940 & 940 & 940 & 940 \\
\hline \multirow[t]{2}{*}{ (3) Unknown causes } & \multicolumn{3}{|l|}{ Men } & \multicolumn{3}{|l|}{ Women } \\
\hline & $20-39$ & $40-64$ & 65 and over & $20-39$ & $40-64$ & 65 and over \\
\hline \multirow[t]{2}{*}{ Unemployment rate } & -0.115 & 0.032 & 1.670 & 0.049 & 0.003 & 0.472 \\
\hline & $(0.095)$ & $(0.404)$ & $(1.253)$ & $(0.061)$ & $(0.131)$ & $(0.618)$ \\
\hline \multirow[t]{2}{*}{ Divorce rate } & 0.492 & $4.282 * *$ & 8.659 & -0.554 & 1.248 & 4.805 \\
\hline & $(0.920)$ & (1.954) & $(6.861)$ & $(0.344)$ & $(0.765)$ & (3.517) \\
\hline$R^{2}$ & 0.319 & 0.826 & 0.875 & 0.275 & 0.600 & 0.857 \\
\hline$N$ & 940 & 940 & 940 & 940 & 940 & 940 \\
\hline
\end{tabular}

Table entries are linear regression estimates with standard errors in parentheses. The unit of observation is prefecture-year. The standard errors are clustered by prefecture. The outcome variables are the mortality rates per 100,000 population by suicide in panel (1), unidentified intent in panel (2), and unknown causes in panel (3). All models include prefecture and year fixed effects and prefecture-specific linear time trends. $* p<0.10, * * p<0.05, * * * p<0.01$ (two-tailed tests).

the sociodemographic indicators, except between the divorce rate and mortality rate due to unknown causes among men aged 40-64.

\section{Discussion}

This study examined the possibility that suicide is underreported in Japan. Using prefecture-level data between 1995 and 2016, we examined whether suicide rates were negatively correlated with mortality rates due to unidentified intent or unknown causes. Our analysis found that suicide rates decreased rapidly among middle-aged and elderly populations and the mortality rates due to unknown causes increased rapidly among senior men and women in recent years of our study period. However, the results of our fixedeffect regression indicated that there was no significant relationship between these mortality rates. Thus, once we consider the effects of various underlying factors, there is no statistically significant relationship between the mortality rates due to suicide and unknown causes, suggesting that it is unlikely that suicidal cases were recoded and counted as deaths due to unidentified intent or unknown causes. Moreover, unemployment and divorce rates had a significant, positive relationship with male suicide rates; no such relationship was found with the mortality rates due to unidentified intent and unknown causes. Thus, these results offer little evidence for the possibility that suicidal cases were classified as deaths due to unidentified intent or unknown causes.

We checked the robustness of our findings in several ways. First, we included the mortality rate by accidents, including traffic accidents and drowning, as another righthand side variables and estimated Eq. (1). The results were generally consistent with those in Table 3; the mortality rate due to accidents had no significant relationship with suicide rates. Second, we confirmed that the results reported in Table 3 held true even after unemployment and divorce rates were included on the right-hand side of Eq. (1). Third, 
we also confirmed that the mortality rates transformed into a natural log did not change the results.

Our findings offer no strong evidence for the possibility of underreporting suicidal deaths in the Japanese context. Varnik et al. [21] proposed that suicide statistics can be considered valid if the mortality rate due to unidentified intent is below 2.0/100,000 and the proportion of deaths due to unidentified intent to suicide is below $20 \%$. According to this $2-20$ benchmark, the suicide statistics in Japan is mostly valid (see Table 2).

This study has a couple of limitations. First, most importantly, our findings cannot be viewed as direct evidence to show that suicides are not underreported in Japan. We only showed that suicidal deaths were unlikely to be recorded as deaths due to unidentified intent and unknown causes, and that the two major determinants of suicide were uncorrelated with deaths due to unidentified intent and unknown causes. To reject the possibility of underreporting of suicide, we need to rely on a more direct approach, such as examining detailed individual death records categorized as deaths by accidents, unidentified intent, or unknown causes, and assess the process of classification. Second, our data excluded death records without information on the date or place of death. This might result in the undercount of deaths from unknown causes or intent because the cause of death was more likely to be unidentified when the details of deaths were unknown.

Acknowledgements This work was financially supported by Japan Society for the Promotion of Science Grants-in-Aid for Scientific Research Grant Numbers 17H02541 and 20H01584. The authors would like to thank Haruko Noguchi and Akira Kawamura for their help with the acquisition of the Vital Statistics data.

Funding This work was financially supported by JSPS Grants-in-Aid for Scientific Research Grant Numbers 17H02541 and 20H01584. The funders had no role in study design, data collection and analysis, decision to publish, or preparation of the manuscript.

\section{Declarations}

Conflict of interest There are no conflicts of interest to declare.

Availability of data and material The approval to use the Vital Statistics for academic research was obtained from the Ministry of Health, Labor, and Welfare (MHLW) by Haruko Noguchi and Akira Kawamura under Tohatsu-0507-3.The data are not available for public use because the death records from the Vital Statistics of Japan in this study were made available by the Ministry of Health, Labor and Welfare of Japan for research use upon request.

Code availability Available upon request.

Ethics approval No ethics approval was required because this study used anonymized and aggregated government statistics.

Consent to participate Not applicable.
Consent for publication Not applicable.

Open Access This article is licensed under a Creative Commons Attribution 4.0 International License, which permits use, sharing, adaptation, distribution and reproduction in any medium or format, as long as you give appropriate credit to the original author(s) and the source, provide a link to the Creative Commons licence, and indicate if changes were made. The images or other third party material in this article are included in the article's Creative Commons licence, unless indicated otherwise in a credit line to the material. If material is not included in the article's Creative Commons licence and your intended use is not permitted by statutory regulation or exceeds the permitted use, you will need to obtain permission directly from the copyright holder. To view a copy of this licence, visit http://creativecommons.org/licenses/by/4.0/.

\section{References}

1. McCarthy PD, Walsh D (1975) Suicide in Dublin: I. the underreporting of suicide and the consequences for National Statistics. Br J Psychiatry 126:301-308. https://doi.org/10.1192/bjp. 126.4.301

2. O'Carroll PW (1989) A consideration of the validity and reliability of suicide mortality data. Suicide Life Threat Behav 19:1-16. https://doi.org/10.1111/j.1943-278X.1989.tb00362.x

3. Rockett I, Kapusta N, Bhandari R (2011) 09/25 Suicide misclassification in an international context: revisitation and update. Suicidol Online 2:48-61

4. Sainsbury P, Jenkins JS (1982) The accuracy of officially reported suicide statistics for purposes of epidemiological research. J Epidemiol Commun Health 36:43-48. https://doi. org/10.1136/jech.36.1.43

5. Speechley M, Stavraky KM (1991) The adequacy of suicide statistics for use in epidemiology and public health. Can J Public Health 82:38-42

6. Kapusta ND, Tran US, Rockett IRH, De Leo D, Naylor CPE, Niederkrotenthaler T, Voracek M, Etzersdorfer E, Sonneck G (2011) Declining autopsy rates and suicide misclassification: a cross-national analysis of 35 countries. Arch Gen Psychiatry 68:1050-1057. https://doi.org/10.1001/archgenpsychiatry.2011. 66

7. Snowdon J, Choi NG (2020) Undercounting of suicides: where suicide data lie hidden. Glob Public Health 15:1894-1901. https://doi.org/10.1080/17441692.2020.1801789

8. Timmermans S (2005) Suicide determination and the professional authority of medical examiners. Am Sociol Rev 70:311333. https://doi.org/10.1177/000312240507000206

9. Lindqvist P, Gustafsson L (2002) Suicide classification-clues and their use: a study of 122 cases of suicide and undetermined manner of death. Forensic Sci Int 128:136-140. https://doi.org/ 10.1016/S0379-0738(02)00188-3

10. De Leo D (2015) Can we rely on suicide mortality data? Crisis 36:1-3. https://doi.org/10.1027/0227-5910/a000315

11. Tøllefsen IM, Helweg-Larsen K, Thiblin I, Hem E, Kastrup MC, Nyberg U, Rogde S, Zahl PH, Østevold G, Ekeberg Ø (2015) Are suicide deaths under-reported? Nationwide re-evaluations of 1800 deaths in Scandinavia. BMJ Open 5:e009120. https:// doi.org/10.1136/bmjopen-2015-009120

12. Bakst SS, Braun T, Zucker I, Amitai Z, Shohat T (2016) The accuracy of suicide statistics: are true suicide deaths misclassified? Soc Psychiatry Psychiatr Epidemiol 51:115-123. https:// doi.org/10.1007/s00127-015-1119-x 
13. Li F, Lu X, Ou Y, Yip PSF (2019) The influence of undetermined deaths on suicides in Shanghai, China. Soc Psychiatry Psychiatr Epidemiol 54:111-119. https://doi.org/10.1007/ s00127-018-1596-9

14. Björkenstam C, Johansson LA, Nordström P, Thiblin I, Fugelstad A, Hallqvist J, Ljung R (2014) Suicide or undetermined intent? Popul Health Metr, A register-based study of signs of misclassification. https://doi.org/10.1186/1478-7954-12-11

15. Linsley KR, Schapira K, Kelly TP (2001) Open verdict v. suicide-importance to research. Br J Psychiatry 178:465-468. https://doi.org/10.1192/bjp.178.5.465

16. Ohberg A, Lonnqvist J (1998) Suicides hidden among undetermined deaths. Acta Psychiatr Scand 98:214-218. https://doi.org/ 10.1111/j.1600-0447.1998.tb10069.x

17. Chang SS, Sterne JAC, Lu TH, Gunnell D (2010) "Hidden" suicides among deaths certified as undetermined intent, accident by pesticide poisoning and accident by suffocation in Taiwan. Soc Psychiatry Psychiatr Epidemiol 45:143-152. https://doi.org/10. 1007/s00127-009-0049-x

18. Chan CH, Caine ED, Chang SS, Lee WJ, Cha ES, Yip PSF (2015) The impact of improving suicide death classification in South Korea: a comparison with Japan and Hong Kong. PLoS ONE. https://doi.org/10.1371/journal.pone.0125730

19. Gjertsen F, Johansson LA (2011) Changes in statistical methods affected the validity of official suicide rates. J Clin Epidemiol 64:1102-1108. https://doi.org/10.1016/j.jclinepi.2010.12.015

20. Li F, Yip PSF (2020) How to make adjustments of underreporting of suicide by place, gender, and age in China? Soc Psychiatry Psychiatr Epidemiol 55:1133-1143. https://doi.org/10.1007/ s00127-020-01856-2
21. Värnik P, Sisask M, Värnik A, Arensman E, Van Audenhove C, van der Feltz-Cornelis CM, Hegerl U (2012) Validity of suicide statistics in Europe in relation to undetermined deaths: developing the 2-20 benchmark. Inj Prev 18:321-325. https://doi.org/10. 1136/injuryprev-2011-040070

22. Rockett IRH, Hobbs G, De Leo D, Stack S, Frost JL, Ducatman AM, Kapusta ND, Walker RL (2010) Suicide and unintentional poisoning mortality trends in the United States, 1987-2006: two unrelated phenomena? BMC Public Health 10:705. https://doi. org/10.1186/1471-2458-10-705

23. Tøllefsen IM, Hem E, Ekeberg $\varnothing$ (2012) The reliability of suicide statistics: a systematic review. BMC Psychiatry. https://doi.org/10. 1186/1471-244X-12-9

24. Ministry of Health, Labour and Welfare of Japan (2019) White paper on suicide prevention. https://www.mhlw.go.jp/wp/hakus yo/jisatsu/19/index.html

25. National Policy Agency (2011) On death investigation system to prevent crime oversight. https://www.npa.go.jp/bureau/criminal/ souichi/gijiyoushi.pdf

26. Ministry of Internal Affairs and Communications. (1995-2016) The Basic Resident Register.

27. Ministry of Internal Affairs and Communications (1995-2016) Syst Soc Demogr Stat Soc Indic Prefect.

28. Chen J, Choi YJ, Sawada Y (2009) How is suicide different in Japan? Jpn World Econ 21:140-150. https://doi.org/10.1016/j. japwor.2008.06.001 